\title{
ПОЛИКУЛЬТУРНОЕ ОБРАЗОВАНИЕ В ВУЗАХ РОССИИ И КАЗАХСТАНА: ПРОБЛЕМЫ И ПЕРСПЕКТИВЫ
}

\section{POLYCULTURAL EDUCATION \\ IN UNIVERSITIES IN RUSSIA \\ AND KAZAKHSTAN: PROBLEMS AND PROSPECTS}

N. Seisekeyeva

R. Arzumanova

G. Bokizhanova

Summary: The article deals with the problem of implementing the principles of multicultural education in universities. The authors approach the solution of the problem by identifying the specifics of multicultural education in universities in Russia and Kazakhstan. The article substantiates the growing importance of polycultural education in universities of cooperating countries, reveals the need to consider the principles of polyculturalization in the context of the development of international cooperation between states. The article also substantiates the importance of the role of multicultural education in universities based on the analysis of the specifics of its implementation in the structure of the activities of higher education institutions, notes its components, among which the authors pay significant attention to the strategy of obtaining educational, life, professionally oriented and work experience, as well as experience communicative interaction, effective business communication in a multicultural educational environment, which makes it possible for future specialists to gain invaluable cultural, educational, cultural, professional and communicative experience.

Keywords: multicultural education, university, Russia, Kazakhstan, problems of polyculturalization, communicative factor, prospects.
B условиях современных реалий поликультуризации общества одним из важнейших направлений преобразований в высшей школе становится подготовка будущих специалистов к профессиональной деятельности и коммуникативному взаимодействию в поликультурном социуме [11;12].

Усиление взаимодействия и международного сотрудничества стран на сегодняшний день ставит перед системой высшего профессионального образования новые требования, регулирующие успешность самореализации и самоактуализации будущих специалистов в условиях формирующегося глобализированного профессионального поля и рынка труда, в которых, в свою очередь, являются учитываемыми особенности представителей различных культур, в том числе языковых традиций и культуры речевой коммуникации. Коммуникативное взаимодействие носителей разных культур в глобаль-
Сейсекеева Нургуль Балтабаевна

докторант, Докторская школа «Познание, Язык, Образование» Экс-Марсельского Университета, лаборатория АДЕФ(Франция), Преподаватель по контракту Экс-Марсельского Университета,

n.seisekeyeva@sorbonne.kz

Арзуманова Раиса Аркадьевны

К.п.н., доцент, Российский университет дружбы народов arzumanowa@mail.ru

Бокижанова Галина Каскарбековна К.n.н., дочент, Академия «Bolashaq», Караганда, Казахстан Galiyakaz68@gmail.com

Аннотация: В статье рассматривается проблема реализации принципов поликультурного образования в вузах. Авторы подходят к решению проблемы через выявление специфики поликультурного образования в вузах России и Казахстана. В статье обосновывается возрастающая значимость поликультурного образования в вузах сотрудничающих стран, раскрывается необходимость учета принципов поликультуризации в условиях развития международного сотрудничества государств. Также в статье дается обоснование значения роли поликультурного образования в вузах исходя из анализа специфики его реализации в структуре деятельности учреждений высшего образования, отмечаются ее составляющие, среди которых авторы уделяют значительное внимание стратегии получения обучающимися образовательного, жизненного, профессионально ориентированного и трудового опыта, а также опыта коммуникативного взаимодействия, эффективного делового общения именно в поликультурной образовательной среде, что дает возможность будущим специалистам получить неоценимый культурно-образовательный, культурно-профессиональный и коммуникативный опыт.

Ключевые слова: поликультурное образование, ВУЗ, Россия, Казахстан, проблемы поликультуризации, коммуникативный фактор, перспективы.

ном профессиональном поле деятельности обусловливает развитие нового качественного уровня взаимоотношений и между странами, и непосредственно между образовательными учреждениями, которые становятся включенными в международное образовательное пространство, где вынуждены взаимодействовать наиболее эффективно [14].

Поликультурное образование как фактор увеличения миграционных потоков и интенсификации сотрудничества/взаимодействия представителей различных культур приобретает сегодня эскалационное значение для многонациональных государств, которые стремятся к признанию автономности, самостоятельности и уникальности существующих культурных потоков, взаимообогащению и взаимодополняемости культур, что необходимо рассматривать не как ассимиляционный процесс, а как процесс сохранения и уважения культур 
в их многообразии. Однако тем не менее, коммуникативное взаимодействие представителей различных культур требует единой речевой кодификации, в рамках которой культурный обмен становится не только возможным, но и продуктивным [8; 9; 10].

Рассматривая систему высшего профессионального образования в рамках его поликультуризации, считаем необходимым выделить ряд общих тенденций его развития как внутри (исторически обусловленных) многонациональных государств (например, Россия, Казахстан, Армения, Белоруссия и др.), так и между самими странами $[2 ; 4]$.

Обоснование значения роли поликультурного образования в вузах диктует необходимость анализа специфики его реализации в структуре деятельности учреждений высшего образования. Нужно отметить, что структура специфики достаточно универсальна и отражена в таких ее составляющих как:

- обучающиеся, выступающие так называемыми звеньями организации программ поликультурного образования (например, обменных образовательных, программ обучения русскому языку как иностранному на довузовских этапах подготовки и т.д.), индивидуальной академической мобильности, а также составляющие число тех иностранных граждан, которые обучаются в вузах в рамках возможностей потоков миграции и т.п.;

- профессорско-преподавательский состав вуза, реализующий потенциал поликультурного образования в учреждении в совместной научно-исследовательской деятельности, индивидуальной мобильности (например, обмен вузов преподавателями), разработке совместных учебных программ (учитывающих поликультурный и лингвокультурный контекст образования), организации профориентационной деятельности, интенсивных образовательных курсов, всевозможных дополнительных школ, включающих также и исследовательские практики обменнокультурного и коммуникативно-языкового значения и т.п.;

- процесс сертификации, достижения необходимого рейтингового положения, уровня достижений, что выражается в таких показателях как способность выдачи «двойных дипломов» (например, для сотрудничающих стран в сфере поликультурного образования), оптимальность системы зачетных единиц, уровень и качество образования, рейтинг документов об образовании на международном рынке образовательных услуг и профессий, спрос и трудоустройство специалистов, способных осуществлять профессиональную деятельности в условиях поликультуризации профессии и пр.; данный аспект особенно важен для вузов сотрудничающих стран, разрабатывающих стратегии зон совместного экономического развития (к таким вузам, например, сегодня необходимо относить учреждения высшего профессионального образования России и Казахстана, осуществляющих подготовку специалистов для совместной профессиональной деятельности на территории государств);

- ряд аспектов поликультурнообусловленного международного сотрудничества, раскрывающих сущность и характер сопутствующей деятельности иных структур в развитии поликультурного образования в сотрудничающих вузах, как, например, качество управления материальными и человеческими ресурсами, управление рисками, программы поликультурного сотрудничества и обмена, а также вопросы организации управления инфраструктурами, связанными с проблемами информатизации, предоставления консультативных услуг в условиях поликультурного обучения, разработкой фонда удовлетворяющих условиям поликультурного образования и сотрудничества оценочных средств и процедур их проведения и т.д. $[1 ; 5 ; 6 ; 7 ; 13 ; 15]$.

Таким образом, просматривается основной концепт специфики поликультурного образования - прогрессивная динамика в увеличении численности студентовносителей различных культур/национальностей, активная академическая мобильность, в процессе которой реализуется стратегия получения обучающимися образовательного, жизненного, профессионально ориентированного и трудового опыта, а также опыта коммуникативного взаимодействия, эффективного делового общения именно в поликультурной образовательной среде, что дает возможность будущим специалистам получить неоценимый культурно-образовательный, культурно-профессиональный и коммуникативный опыт из «первых рук» и, тем самым, обогатить сферу своих общекультурных и профессиональных компетенций, знаний, умений и навыков из источников успешных, интернационально признанных и культурно разнообразных.

Чтобы наиболее эффективно классифицировать условия поликультурного функционирования вузов в области подготовки будущих профессионалов, необходимо понимать, на основе каких принципов рациональности и эффективности они будут регулироваться. Рассмотрим подробнее основные механизмы и аспекты данной регуляции.

Начиная анализ условий поликультурного образования в вузах (в нашем случае в вузах России и Казахстана) в контексте тенденций современной системы образования, мы исходили из концепции его интеграции в поликультурное многонациональное (в том числе международное) образовательное пространство, ре- 
гулирующееся на основе следующих принципиальных подходов к его организации и проведения единой образовательной политики, среди которых имеют место следующие:

- неуклонный рост престижа поликультурного образования и его качества, включая высокий уровень владения деловой коммуникацией (что реализуется в процессе освоения языковых дисциплин, в том числе русского языка как иностранного, русского языка и культуры делового общения и пр.);

- достижение масштабности в рамках формирующегося поликультурного пространства при переходе к двухуровневой системе образования высшего образования, подразумевающей реализацию образовательных программ бакалавриата и магистратуры с получением опыта деловой коммуникации в условиях неродной языковой среды;

- поиск и реализация путей сотрудничества образовательных учреждений стран с целью обеспечения качества поликультурного образования, отражающего европейские каноны качества;

- на основе реализации путей и условий реализации поликультурной политики в вузе обеспечение содействия академической мобильности студентов, профессорско-преподавательского состава, кадров научно-исследовательских областей и единиц административных и вспомогательных служб;

- обеспечение регулирования получения высшего образования в аспекте глобализирующейся тенденции поликультуризации образовательной и профессиональной сфер деятельности на основе внедрения сопоставимой и оптимально продуктивной системы зачетных единиц трудоемкости учебных дисциплин с целью достижения роста и эффективности академической мобильности обучающихся.

Таким образом, перечисленные аспекты как индикаторы существующих проблем в сфере поликультурного образования в вузах России и Казахстана предопределяют поиск эффективных путей их решения, причем решение проблем, связанных с языковой подготовкой и овладением деловой коммуникацией, становится одной из приоритетных в условиях формирующей новой лингвокультурной реальности.

Так, например, перспективными направлениями решения данного спектра проблем в вузах России и Казахстана становится разработка специализированных курсов, направленных на формирование профессиональной коммуникативной компетенции в поли- и мультикультурной средах. Одним из таких эффективных путей решения рассматриваемой проблемы явилась разработка преподавателями РУДН спецкурса «Профес- сиональное общение в мультикультурной среде», который успешно реализуется в настоящее время.

Однако необходимо отметить, что в условиях цифровизации образования становится нарастающей проблема информатизации обучения, в рамках которой учет принципов поликультурности при формировании профессиональной коммуникативной компетенции в настоящее время реализуется недостаточно. Так, например, известно, что обучающиеся из Казахстана как многонационального государства, нуждаются в электронном обеспечении процесса овладения, например, русским языком (как языком профессиональной коммуникации в дальнейшем), в то время как такие электронный образовательные ресурсы не разработан еще в достаточное мере: отсутствуют двуязычные словари, учитывающие язык национальных меньшинств, этносов, которые могут быть продуктивно использованы в рамках поликультурного языкового образования как средства восприятия лексикографической фиксации лексического материала; только начинает реализовываться аудио поддержка таких словарей (в вузах России); в условиях поликультуризации образования в рамках сотрудничества вузов России и Казахстан имеет широкую востребованность разработка интерактивных ресурсов обучения языку на основе феномена языковой интерференции (это важно для вузов Казахстана, где необходим учет фактора многонациональности), на основе визуализации работы артикуляционного аппарата и др., позволяющих обучающимся формировать индивидуальные образовательные маршруты языковой интерактивной подготовки в условиях поликультурного обучения [3].

В настоящее время в вузах России и Казахстана осуществляется языковая подготовка обучающихся, которая реализуется параллельно с программой профессиональной подготовки на этапе начальной профессиональной самореализации, однако тем не менее, такое параллельное обучение вызывает затруднения у большинства обучающихся, так как недостаточный уровень владения языком обучения препятствует овладению специальным знанием, в связи с чем разработка образовательных интерактивных/электронных ресурсов для освоения языка в рамках разработанных спецкурсов (которые могут быть реализованы на различных платформах электронного обучения), доступных обучающимся в любое время и из любой точки, являются важным перспективным направлением учета принципов поликультурного образования как принципов преемственности и непрерывности.

Также необходимо отметить, что на сегодняшний день в вузах практически отсутствуют программы развития межкультурной толерантности, в рамках которых вопросы коммуникативного взаимодействия в поликультурной среде также могут иметь эффективные решения. 
Так, например, подобные программы начинают реализовываться в ВУЗах Москвы (в частности, в Российском университете дружбы народов и др.), где одной из задач становится преодоление языковых барьеров в мультикультурной образовательной среде. В рамках реализации таких программ предусмотрены коммуникативные тренинги (вербальная и невербальная коммуникации в моделируемых ситуациях поликультурного общения обучающихся), на которых используются этнокультурные технологии, технологии коммуникации, коммуникативного сотворчества и др.

Так, актуальность проблем современной педагогики, ориентированной на реализацию гуманистических основ, предопределила использование педагогических технологий, обеспечивающих включенность в них личности иностранного студента на правах субъект-субъектного взаимодействия. К таким технологиям была отнесена технология сотворчества (т.е. технология, позволяющая студенту реализовать свою способный творить и совершенствоваться одновременно с педагогом и студентам старших курсов).

Также в процессе реализации программы были использованы другие технологии инновационного характера, позволяющие одновременно удовлетворить решению задач воспитательно-образовательного значения с целью получения нового более высокого уровня сформированности межкультурной толерантности иностранных студентов.

Среди реализуемых технологий в перспективных направлениях поликультурного образования в вузах России и Казахстана становятся популярными технологии, обеспечивающие:

- возможность эффективного формирования профессиональной коммуникативной компетенции, способствующей эффективной положительной социализации личности иностранных студентов в поли- и мультикультурной образовательной среде;

- возможность продуктивной передачи социальнокультурного опыта посредством формирования языковых компетенций (орфоэпической, фонетической, коммуникативно-речевой и др.), позволяющих осуществлять анализ и оценку различных ситуаций поликультурного взаимодействия на этапе начальной профессиональной самореализации;

- возможность формировать способность иностранного студента к творческой организации различных дел в рамках интеграции в поликультурную образовательную среду вуза;

- возможность фокусировать поликультурный творческий опыт на создании ситуаций профессионального успеха и др.

Перечисленные основные аспекты регулирования и перспективы развития поликультурного образования в вузах России и Казахстана обозначили объективность следующих принципов организации сотрудничества вузов и реализации условий поликультурного образования: принцип приоритетности, раскрывающийся в направленности образовательной политики сотрудничества вузов на обеспечение высокого качества и престижа поликультурного образования, позволяющего удовлетворять конкурентоспособности и спросу международного рынка услуг и труда на специалистов, способных реализовать свои профессиональные возможности в условиях формирующейся единой лингвокультурной реальности; принцип равноправности, заключающийся в равноправии вузов-партнеров, характеризующихся спецификой сотрудничества и поликультуризации образования, определяющейся различными факторами: вузовской специализацией, ресурсами образовательного учреждения, имеющегося опыта интернационализации, регионально-географической локализации и др.; принцип гостеприимства, который выражается в привлечении как можно большего количества студентов-носителей различных культур, их поддержке, совершенствовании качества образовательных программ, улучшении инфраструктуры и условий пребывания студентов, а также развитии программ культурного обмена и пр.

Важнейшим аспектом политики развития поликультурного образования также остается необходимость анализа национальных образовательных систем и экстраполяции национальных принципов регулирования образовательной политики в единое поликультурное образовательное пространство с учетом автономности/ самостоятельности и уникальности разнообразия национальных культур.

\section{ЛИТЕРАТУРА}

1. Абдуразакова Д.М., Берсенукаева М.Х. Роль поликультурной среды в воспитании и развитии толерантности молодёжи // Мир науки, культуры, образования. -2019. - № 2 (75). - С. 10-11.

2. Апанасенко 0.М. Философское обоснование и сущностные характеристики поликультурности в образовании // Вестник Пермского государственного гуманитарно-педагогического университета. Серия № 1. Психологические и педагогические науки. - 2018. - № 2, 2018. - С. 138-145. doi:10.24411/2308-7218-2018-00033

3. Бирюкова 0.И., Морозова Е.Н. Поликультурное образование в условиях республики Казахстан: современное состояние проблемы // Гуманитарные науки 
и образование. - 2018. - № 1(33). - С. 7-12.

4. Геворкян М. Поликультурное образование в Армении: новая стратегия развития образования // 21-й век. - 2017. - № 2 (43). - С. 103-115.

5. Грузкова С.Ю., Гильмеева Р.Х., Камалеева А.Р., Мухаметзянова Л.Ю. Когнитивные механизмы формирования поликультурной толерантности обучающихся в образовательной среде // Казанский педагогический журнал. - 2018. - № 5 (130). - С. 112-120.

6. Кац А.С. Формирование межэтнической толерантности как основа диалога культур в контексте поликультурного образования студентов вузов // Казанский педагогический журнал. - 2017. - № 2 (121). - С. $42-45$.

7. Корякина А.А. К вопросу о формировании толерантности в поликультурном образовательном пространстве // Азимут научных исследований: педагогика и психология. - 2019. - № 1 (26). - С. 179-182.

8. Макажанова Ж.М. Поликультурность в современном образовании, или чем отличается поликультурность от мультикультурализма // Непрерывное образование: XXI век. - 2018. - № 3 (23). - С. 106-113.

9. Пономарев П.А. Роль поликультурного образования в современных условиях // Известия высших учебных заведений. Северо-Кавказский регион. Общественные науки. - 2011. - № 1. - С. 140-143.

10. Расчетина С.А. Поликультурное образование как средство межкультурного диалога // Человек и образование. - 2017. - № 3 (52). - С. 37-44.

11. Современные проблемы образования в поликультурном регионе (Шестые Лозинские чтения): Материалы Международной научно-методической конференции 23-24 апреля 2015 г. Часть І. - Псков: Псковский государственный университет, 2015. - 324 с.

12. Супрунова Л.Л. Поликультурное образование как важное направление модернизации школы в постиндустриальном обществе // Отечественная и зарубежная педагогика. - 2014. - № 3 (18). - С. 81-88.

13. Трегубова Т.М. Международные проекты поликультурного образования студентов в условиях современных проблем глобализации // Вестник Нижегородского университета им. Н. И. Лобачевского. Серия: Социальные науки. - 2015. - № 3 (39). - С. 194-199.

14. Халимон Е.А. Условия и факторы успешного сотрудничества вузов России и зарубежных стран // Вестник университета. - 2017. - № 9. - С. $51-59$.

15. Шайхутдинова Г.А., Трегубова Т.М. Кац А.С. Международный опыт как ресурс совершенствования системы обучения и воспитания студентов вузов // Казанский педагогический журнал. - 2018. - № 5 (130). - С. 107-111.

( Сейсекеева Нургуль Балтабаевна (n.seisekeyeva@sorbonne.kz), Арзуманова Раиса Аркадьевны (arzumanowa@mail.ru ), Бокижанова Галина Каскарбековна (Galiyakaz68@gmail.com).

Журнал «Современная наука: актуальные проблемы теории и практики»

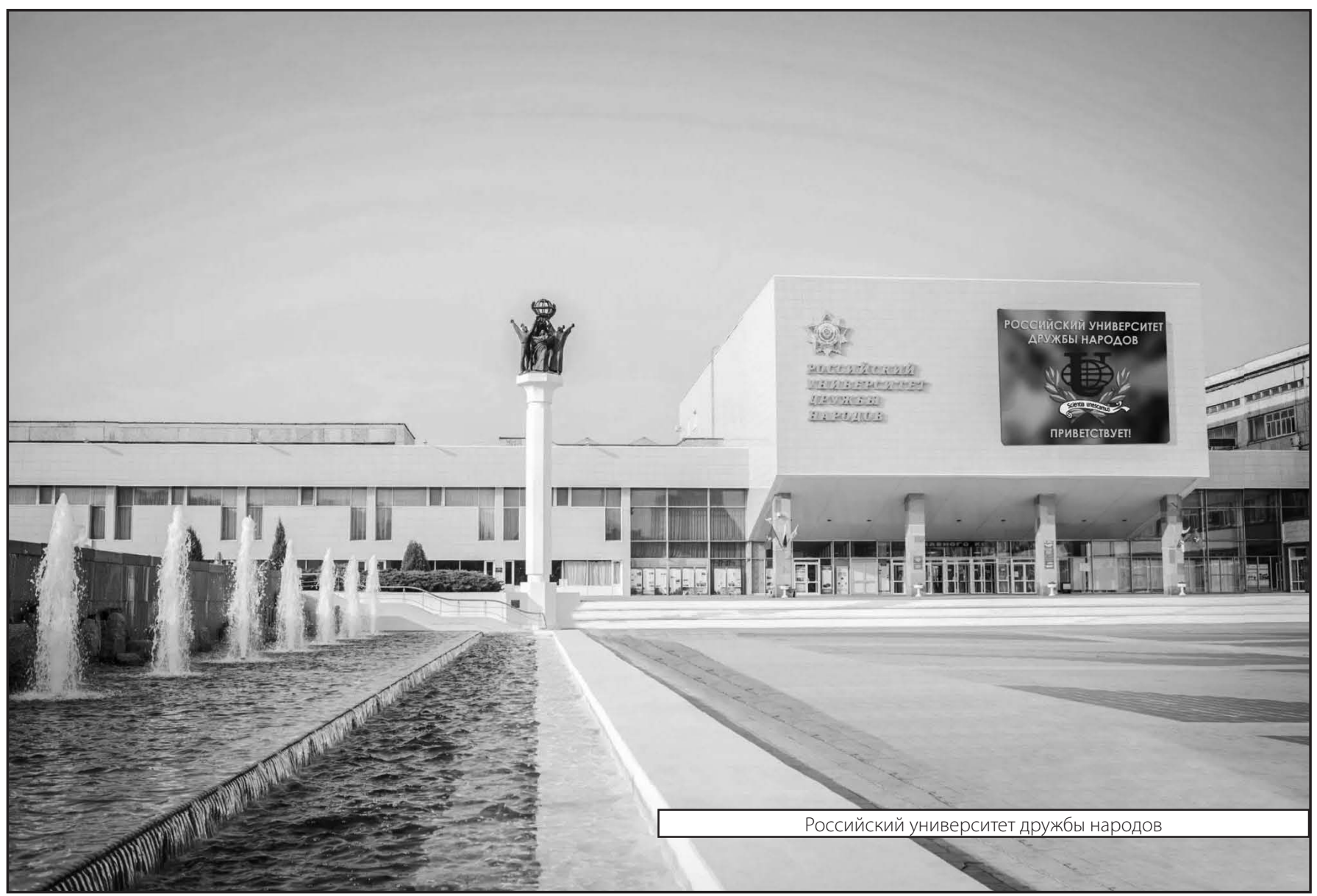

